\title{
Educação e Desigualdade: A Conjuntura Atual do Ensino Público no Brasil
}

\author{
Jurandir de Almeida Araújo \\ Mestre em Educação e Contemporaneidade pela Univer- \\ sidade do Estado da Bahia (Uneb). Membro do Grupo \\ de Pesquisa Educação, Desigualdade e Diversidade e da \\ Associação Brasileira de Pesquisadores(as) pela Justiça \\ Social (Abrapps). Professor formador do curso de História \\ EaD da Uneb. juran-araujo@hotmail.com
}

\section{Resumo:}

Os indicadores sociais e educacionais revelam que as oportunidades educacionais, no Brasil, não são iguais para todos os grupos sociais e étnico-raciais. Há uma diferença bastante expressiva entre ricos e pobres, brancos e negros no acesso à educação formal no país. Assim, o presente artigo tem como objetivo analisar e refletir sobre as desigualdades que permeiam o sistema educacional brasileiro. Com base nos indicadores sociais e nos estudos que discutem a temática, apresenta-se uma breve análise da conjuntura atual em que se encontram os grupos menos favorecidos, em particular, a população negra, no sistema de ensino; discussão necessária para percebermos alguns dos mecanismos que determinam o lugar dos diferentes grupos sociais e étnico-raciais na sociedade brasileira. 0 estudo evidenciou que, nos últimos anos, algumas políticas educacionais, contemplando a diversidade étnico-racial e cultural do povo brasileiro, foram criadas pelo Estado com o objetivo de minimizar as desigualdades existentes na educação. Evidenciou também que as desigualdades são mais exacerbadas para a população negra e nas regiões menos desenvolvidas economicamente - Norte e Nordeste -, e que, mesmo com os avanços que se tem conseguido, o desempenho educacional dos brasileiros é insatisfatório. Se comparado com outros países de níveis semelhantes de desenvolvimento e renda per capita, o Brasil só consegue superar os países pobres da América Latina.

Palavras-chave: Democratização. Desigualdades. Grupos étnico-raciais. Regiões pobres. 


\title{
EDUCATION AND INEQUALITY: THE CURRENT SITUATION OF PUBLIC EDUCATION IN BRAZIL
}

\begin{abstract}
:
Educational and social indicators reveal that educational opportunities in Brazil are not the same for all social groups and ethnic-racial. There is a very significant difference between rich and poor, whites and blacks in access to formal education in the country. Thus, this article aims to analyze and reflect on the inequalities that permeate the Brazilian educational system. Based on social indicators and studies that discuss the topic, presents a brief analysis of the current situation in which they are disadvantaged groups, in particular, the black population in the school system. Talk necessary to realize some of the mechanisms that determine the place of different social groups and ethnic-racial in Brazilian society. The study showed that, in recent years, some educational policies, considering the ethnic and racial diversity and cultural Brazilian people, were created by the state in order to reduce existing inequalities in education. Also showed that inequalities are more exacerbated for the black population and the economically less developed regions, north and northeast, and that even with the advances that have been achieved, the educational performance of the Brazilians is unsatisfactory. Compared with other countries of similar levels of development and income per capita, Brazil only beat the poor countries of Latin America.
\end{abstract}

Keywords: Democratization. Inequalities. Racial-Ethnic Groups. Poor regions.

\section{Sumário}

1 Introdução. 2 Panorama das desigualdades educacionais no Brasil. 3 As desigualdades educacionais na Região Nordeste e na Bahia 4 Considerações finais 5 Referências 


\section{INTRODUÇÃO}

A expansão do ensino público, no Brasil, se dá a partir da segunda metade do século 20 , influenciada pelo processo de industrialização e urbanização da sociedade brasileira, processo que provocou mudanças significativas na estrutura social e política do país. Dentre essas mudanças destaca-se a prioridade do Estado por educação, que, até aquele momento, era privilégio de poucos. Ou seja, até meados do século 20 a educação era um privilégio dos grupos mais favorecidos; o ensino público era tido como de boa qualidade, pois se tratava de uma escola que pagava bons salários aos professores e possuía infraestrutura e equipamentos adequados, mas era reservado para uma pequena parcela da população (a elite), enquanto a grande maioria da população pobre, notadamente negros e indígenas, que mais necessitava de instrução, era excluída do acesso ao sistema de ensino formal.

Até 1967, quando é introduzida a escolaridade obrigatória e gratuita de oito anos, poucos foram os sujeitos pertencentes aos grupos menos favorecidos que conseguiram ter acesso à educação formal no Brasil. Com a obrigatoriedade do ensino básico, embora a oferta de vagas ainda fosse bastante reduzida, a escola pública brasileira se converte em uma instituição garantidora da igualdade de acesso de todos à educação, iniciando-se assim o processo de democratização do ensino público no país (Araújo, 2012).

O processo de democratização da educação pública no Brasil, no entanto, não significou o fim das desigualdades no sistema de ensino. Como afirma Haddad (2007, p. 31), "os avanços na oferta de escolaridade dos brasileiros não alteraram o quadro das desigualdades na educação”. O Estado buscou garantir o acesso de todos, mas não criou condições para que esses novos sujeitos que adentraram na escola, em sua maioria negros, permanecessem e saíssem dela com êxito, ou seja, não criou as condições necessárias para a igualdade de oportunidades. Com a obriga- 
toriedade do ensino básico as desigualdades de acesso dos grupos menos favorecidos foram substituídas pelas desigualdades de sucesso no interior do sistema de escolar (Dubet, 2008; Oliveira; Araújo, 2005).

Com a democratização passou, também, a se buscar a universalização do ensino. Busca essa que influenciou categoricamente para o processo de sucateamento e privatização do sistema escolar público, isto é, para a fuga dos grupos mais afortunados para o sistema de ensino privado. Para Arroyo (2003, p. 30)

a expansão da escola básica popular se torna realidade não tanto porque o mercado tem exigido maior escolarização, nem porque as elites se tornaram mais humanitárias, mas pela consciência social reeducada pelas pressões populares.

Complementando o pensamento de Arroyo (2003), Gomes (2011, p. 134) afirma que:

Quanto mais aumenta a consciência da população pelos seus direitos, mais a educação é tomada na sua especificidade conquanto direito social. E mais, como um direito social, que deve garantir nos processos, políticas e práticas educativas a vivência da igualdade social, da equidade e da justiça social aos diferentes grupos sociais e étnico-raciais.

Nesse sentido, pode-se afirmar que a busca por educação, no Brasil, é uma reivindicação antiga dos grupos menos favorecidos, a exemplo dos negros, que, desde suas primeiras organizações, pós-abolição da escravatura, colocou-a como prioridade de suas ações. Arroyo (2009, p. 153), ressalta, no entanto, que

reconheçamos que não conseguimos ainda colocar a educação no campo dos direitos sociais humanos plenos, ela fica à mercê de tantos condicionantes sociais, raciais, territoriais e até escolares, que não acaba de se afirmar como obrigatória. 
Acrescenta, ainda, que cada sujeito pertencente aos grupos menos favorecidos que for a busca "do seu direito a um percurso de formação digno, ininterrupto, terá de aprender que tem apenas $20 \%$ de chance de garantir esse direito. Estará entre os $80 \%$ dos reprovados, repetentes, multirrepetentes, defasados, evadidos” (Arroyo, 2009, p. 153).

As observações de Arroyo evidenciam que a educação formal brasileira ainda não contempla os anseios dos grupos menos favorecidos. As escolas públicas não apresentam o mínimo de infraestrutura. Os quadros de docentes e funcionários não estão preparados para o exercício de suas funções, "por falta de uma política voltada para o setor educacional, principalmente para o ensino básico" (França, 2008, p. 86). A falta de políticas educacionais que atinjam a raiz do problema, e os avanços e retrocessos políticos, econômicos e sociais, influenciam decisivamente para a conjuntura atual em que se encontra a educação pública no Brasil. Ou seja, se, por um lado, o sistema público de ensino encontra-se democratizado e universalizado ou em via de universalização, por outro segue existindo mecanismos que mantêm as desigualdades na educação.

No que se refere à situação da população negra no acesso à educação formal, Gonçalves e Silva (2000) assinalam que existem questões no passado que explicam nitidamente os graves problemas educacionais que afligem a maioria dos negros brasileiros na atualidade. Em outras palavras, as dificuldades educacionais que atingem os afro-brasileiros nos dias de hoje têm origem desde os tempos mais longínquos da história da educação brasileira e está estruturada sobre dois eixos: exclusão e abandono, como assinala Silva (2001, p. 66), "é preciso compreender que a exclusão escolar é o início da exclusão social das crianças negras”. Não só das crianças, mas também dos adolescentes, dos jovens e dos adultos negros, assim como de outros grupos e sujeitos em situações semelhantes. 
É notório que as desigualdades que permeiam o sistema educacional brasileiro atingem todos os sujeitos pobres e carentes de instrução, no entanto com maior intensidade os negros. Percebe-se que se garantiu o acesso, mas que a qualidade da educação oferecida pouco contribui para tirá-los do lugar subalternos a que foram condicionados, tampouco para a melhoria na sua qualidade de vida. A impressão que se fica é que, a cada dia que passa, a qualidade do ensino público brasileiro está cada vez mais precária, principalmente após o processo de democratização e universalização. E, como sempre, são as pessoas pobres, em sua maioria negra, as mais prejudicadas. Como veremos no decorrer deste artigo, os indicadores sociais, em particular os educacionais, revelam o quanto é desigual a proximidade da população negra a bens e serviços, principalmente no acesso aos conhecimentos científicos e aos saberes sistematizados, em comparação com a população branca.

Assim, o presente artigo, originado da pesquisa intitulada "A atuação das Organizações Negras Baianas no campo da educação no período de 1970 a 1990", tem como objetivo analisar e refletir sobre as desigualdades que permeiam o sistema educacional brasileiro, partindo do pressuposto de que as oportunidades educacionais no Brasil não são iguais para todos; garantiu-se o acesso, mas não se garantiu a qualidade. A pesquisa tem como base os indicadores soc iais do Censo 2010 (Instituto..., 2011), PNAD 2009 (Instituto..., 2010), Ideb 2011 (Índice..., 2011), e estudos de autores que discutem a temática, tais como Arroyo (2009), Gomes (2011), Haddad (2007) Hasenbalg (1997, 2005), Queiroz (1999, 2002), entre outros.

\section{PANORAMA DAS DESIGUALDADES EDUCACIONAIS NO BRASIL}

Se comparado com outros países de níveis semelhantes de desenvolvimento e renda per capita, o desempenho educacional do Brasil é insatisfatório; apenas consegue superar os países pobres da América 
Latina. Os indicadores sociais revelam que o país não oferece as mesmas oportunidades educacionais para todos os estratos sociais da população, e que a diferença educacional entre ricos e pobres, brancos e negros é bastante expressiva (Silva; Hasenbalg, 2000). Aqui, as desigualdades sociais e raciais estão refletidas na educação, influenciando negativamente no acesso, na permanência e no êxito dos grupos menos favorecidos e historicamente discriminados, negros e indígenas, nos diferentes níveis e modalidades de ensino.

Para Queiroz (1999, p. 200):

Num país como o Brasil, apontado por exibir alarmantes estatísticas de repetência escolar, sobretudo nos anos iniciais da escolarização, é impossível falar em democratização das oportunidades educacionais sem tocar na questão das desigualdades raciais vigentes.

Ou seja, no Brasil, a educação que se pensa democrática ainda não oferece oportunidades iguais para todos os brasileiros. Os indicadores sociais revelam o grande fracasso que é o ensino público, hoje, no país. De acordo com Barcelos (1993), os baixos índices educacionais são umas das características mais marcantes do desempenho escolar brasileiro e a repetência um problema central que atinge, especialmente, os mais pobres. Segundo o referido autor, “o fracasso do sistema educacional se faz sentir sobretudo no desempenho de pretos e pardos” (Barcelos, 1993, p. 23), corroborando para o que afirma Queiroz (1999) na citação anterior, de ser impossível falar em democratização da educação sem discutir desigualdades raciais.

Conforme os estudos de Hasenbalg (1997, p. 64), “o sistema educacional no Brasil funciona como um grande filtro ou peneira em matéria de distribuição de oportunidades sociais”. No que se referem à desigualdade étnico-racial, o autor citado nos chama a atenção para o fato de que esta "é gerada tanto na fase preparatória de educação formal como na posterior ao ingresso no mercado de trabalho" (Hasenbalg, 1997, p. 65). 
Em outras palavras, em todas as fases da vida os negros brasileiros vão encontrar obstáculos para se desenvolverem plenamente como sujeitos e como cidadãos de direitos, até mesmo aqueles que têm uma condição financeira mais elevada.

Para Haddad (2007, p. 32), “a falta de qualidade do ensino básico é uma das principais causas dos problemas educacionais no Brasil e do baixo nível de escolaridade da população”, pois, a seu ver, “o ensino sem qualidade induz ao aumento na taxa de reprovação dos alunos, bem como um incremento na taxa de evasão escolar” (Haddad, 2007, p. 32). A repetência e a evasão escolar são problemas que há tempo vêm sendo pesquisados e debatidos pelas escolas, pelas universidades, pelas organizações sociais e por órgãos governamentais, no entanto ainda não se encontrou meios eficazes de resolver tais problemas.

Os indicadores educacionais revelam que, apesar do Ensino Fundamental estar praticamente universalizado, atingindo aproximadamente $97 \%$ da população entre 7 e 14 anos de idade, apenas 52\% dos alunos conseguem concluí-lo. E mais, dos estudantes da $4^{a}$ série (hoje $5^{\underline{0}}$ ano) apenas $4,8 \%$ estão plenamente alfabetizados, $37,7 \%$ medianamente sabem ler e $55,5 \%$ não podem ser considerados como totalmente alfabetizados. O Ensino Médio, em via de universalização, com aproximadamente $85 \%$ dos estudantes entre 15 e 17 anos matriculados, apenas 66,6\% conseguem conclui-lo. No ensino superior, a porcentagem cai vertiginosamente. Apenas cerca de $8 \%$ das pessoas entre 18 e 24 anos têm acesso a esse nível de escolaridade, e 75\% das matrículas estão nas instituições privadas (Castro, 2009; França, 2008), dados esses que permitem afirmar que o que se conseguiu foi a igualdade de acesso da população pobre ao Ensino Fundamental de nove anos, e uma expansão, que também caminha, para a universalização do Ensino Médio, e que, todavia, no ensino superior essa expansão foi irrisória; permitem afirmar também que, numa época 
como a atual, em que a educação assume papel de destaque em todos os setores da sociedade, principalmente no setor econômico, esses dados são assustadores.

É do conhecimento de todos que na contemporaneidade quanto maior for o nível de escolaridade do indivíduo maior será sua chance de manter-se competitivo no mercado de trabalho, assim como participante ativo nas relações de poder, enquanto para aquele de pouco estudo resta-lhe apenas a condição de subalterno e, em muitas situações, de marginalizado. Se, entretanto, a educação é, hoje, uma das condições básicas para se viver em sociedade, o que justifica o baixo nível de escolaridade da maioria dos brasileiros? Segundo Haddad (2007, p. 24), "no Brasil, são quase 68 milhões de pessoas acima de 14 anos que não têm o que é considerado por lei um direito: o ensino fundamental de 8 anos ${ }^{1}$. Destes, apenas 7,6 milhões estão hoje estudando”. Complementando a observação de Haddad, Klein (2006) afirma que o acesso à escola no Brasil está universalizado, mas a conclusão do Ensino Fundamental e Médio está longe de ser universalizado.

Nesse processo desigual e excludente que é a educação formal no Brasil, as oportunidades de acesso, permanência e êxito dos grupos menos favorecidos, notadamente a população negra e a indígenas, ao sistema de ensino, não são as mesmas dos grupos mais favorecidos. Existe uma diferença bastante expressiva entre ricos e pobres, brancos e negros no acesso aos diferentes níveis e modalidade de ensino no país. A esse respeito, Soares e Alves (2003, p. 149) são enfáticos ao afirmarem que, ainda que se manifestem de forma menos maciça e mais sutil, moduladas por "filtros socioeconômicos, raciais, localização (urbana, rural) e por tipo de rede escolar (pública, particular)”, as desigualdades no acesso aos diferentes níveis de ensino ainda persistem nos dias atuais.

${ }^{1}$ Observação: O Ensino Fundamental no Brasil aumentou de oito para nove anos. 
Para Arroyo (2009, p. 153),

o mais grave em nosso lento avanço na garantia do direito à educação básica é que as vítimas desses direitos negados em percursos truncados não terão a quem apelar. Diante da segregação social escolar, não tem apelação.

\section{Afirma o referido autor que}

falta em nossa cultura política criarmos hábitos de apelar ao judiciário em defesa do direito à educação, ao acesso e à permanência, ao direito a um percurso de formação digno, sem interrupção, retenção ou defasagens (Arroyo, 2009, p. 153).

Estudos e pesquisas, como de Barcelos (1993), Bock (2009), Castro (2009), França (2008), Hasenbalg (2005, 1997), Queiroz (1999, 2002), Reiter e Dias (2005), Silva e Hasenbalg $(2000,1998)$, entre outros, revelam que as desigualdades que permeiam o sistema escolar brasileiro são de ordens diversas - renda, cor/raça, sexo, região, campo/cidade, etc. -, influenciando decisivamente para que as oportunidades educacionais no Brasil não sejam iguais para todos. A esse respeito, Silva (2007, p. 165) afirma que

a complexa inter-relação entre raça, cor, posição social e nível educacional no Brasil está baseada em relações hierarquizadas e posicionamentos sociais sempre ambivalentes, dependentes de situações cotidianas e de contextos específicos.

A ausência de políticas públicas efetivas de combate às desigualdades sociais afetam principalmente os grupos historicamente excluídos do sistema de ensino, a exemplo de negros, de índios, de mulheres, de camponeses, entre outros, "gerando situações de iniqüidade no que diz respeito ao acesso e à permanência no sistema educacional”, como ressalva Haddad (2007, p. 7), grupos que se encontram reféns de um sistema capitalista, no qual quem pode mais são os indivíduos que têm maior poder aquisitivo, os quais em sua maioria são brancos e pertencentes à cultura hegemônica - europeia. 
As desigualdades, visíveis e identificadas, que perpassam pelo sistema educacional brasileiro, parecem não servir de parâmetro para mudar a precária situação da educação pública no Brasil (ARAÚJO, 2012). As análises do Instituto de Pesquisa Econômica Aplicada (IPEA) sobre a Pesquisa Nacional por Amostra de Domicílios (PNAD, 2009) concluíram que a desigualdade ainda é um dos grandes desafios quando se trata de melhorar a educação no país. Conforme essas análises, os dados coletados revelam que os grupos sociais mais ricos gastam $30 \%$ a mais com educação que os mais pobres, e no nível da Pós-Graduação e de cursos de idiomas o gasto com educação chega a ser praticamente nulo para os mais pobres. A esse respeito, Tavares Junior (2011, p. 554) afirma que "a origem social desempenha um papel muito importante para determinação dos destinos sociais de todos os estratos sociais, em especial aos superiores, e para todos os níveis de ensino".

Complementando o pensamento de Tavares Junior, Arroyo (2009, p. 139) salienta que:

\begin{abstract}
A frase pobre, negro, caboclo, do campo, da favela, "fique no teu lugar" faz parte de nossa cultura política. Há lugares assinados para cada coletivo. Sair do lugar social, racial, de gênero não tem sido fácil em nossos padrões de produção, de poder e de trabalho, de cultura e de conhecimentos. Somente provando, mostrando ter capacidades requeridas, os valores e conhecimentos, as condutas que ostentem dignos poderão até passar de lugar, de margem.
\end{abstract}

Percebe-se na citação de Arroyo e no decorrer do artigo que segue existindo socialmente, no Brasil, situações favoráveis à sustentação do preconceito e da discriminação de grupos sobre outros. A escola, por exemplo, que deveria ser o lugar privilegiado para a formação de valores, o lugar da alteridade e da construção de direitos, permanece presa a um modelo educacional eurocentrista, monocultural e excludente que 
pouco contribui para o desenvolvimento intelectual, profissional e social dos grupos estigmatizados, oprimidos e marginalizados, que se fazem presentes no seu espaço.

Os estudos de Castro (2009), França (2008) e as análises do IBGE (2011) permitem afirmar que a diferença de renda tem grande impacto no nível de escolaridade da população brasileira. Quanto mais rico for o indivíduo maior será o seu grau de instrução. Resumindo: a situação econômica do sujeito influencia terminantemente para que este tenha ensino de qualidade e nível de escolaridade mais elevado.

A questão geográfica é outro fator que gera desigualdade na educação brasileira. Segundo as análises de Castro (2009), as oportunidades educacionais da população urbana são maiores do que a da população da zona rural, a qual, em comparação à da cidade, tem quatro anos de estudos a menos e um quarto da população é analfabeta, enquanto na zona urbana a taxa de analfabetismo é de 4,4\%. Segundo os dados do Censo de 2010 (IBGE, 2011), a taxa de analfabetismo, no Brasil, até o ano de 2010, chegava a $9,6 \%$, e $90 \%$ dos não alfabetizados tinham mais de 25 anos de idade, e atingia principalmente a população da zona rural. Para o autor citado, “o analfabetismo é ainda um dos grandes problemas sociais a serem enfrentados para a construção da cidadania plena”, no país (Castro, 2009, p. 679).

Conforme a análise do IBGE (2011), em relação ao analfabetismo no país outro dado que chama a atenção é a proporção de crianças de 10 anos de idade que não sabe ler e escrever (6,5\%), reflexo do atraso destas em ingressarem no Ensino Fundamental na idade adequada e/ou da má qualidade do ensino ofertado. Ainda, de acordo com a análise do IBGE, "a alfabetização é requisito indispensável para qualquer nível de desenvolvimento, sendo considerado um parâmetro mínimo para o desenvolvimento humano" (2011, p. 75). 
A desigualdade no Brasil não se reduz apenas à zona rural e urbana, mas também entre regiões. Na Região Sudeste, por exemplo, a população tem dois anos a mais nos anos de estudos em comparação com a população da Região Nordeste. A esse respeito, Bock (2009, p. 2) observa que:

regiões e/ou estratos sociais pobres têm maiores índices de analfabetismo, maior defasagem idade/série, média de número de anos de escolaridade menor e outros aspectos que demonstram que a pobreza e a baixa escolarização caminham juntas.

Ou seja, as desigualdades raciais, sociais e regionais, assim como a baixa escolaridade da população brasileira, são problemas graves que precisam ser superados no país.

Dentre tantos outros fatores que geram desigualdades no sistema educacional brasileiro, a questão étnico-racial é um problema sério que tem de se levar em consideração se realmente desejamos mudar o quadro das desigualdades na educação. Por exemplo, enquanto a taxa de analfabetismo da população negra chega a $14,4 \%$, entre a população branca essa taxa é de 5,9\%, o que evidencia a disparidade entre negros e brancos no acesso à educação formal no Brasil. Os estudos de Castro (2009) e França (2008) nos ajudam a perceber a disparidade entre brancos e negros que cursam o Ensino Médio e o ensino superior na faixa etária considerada adequada. Nesses dois níveis de ensino as diferenças porcentuais também são expressivas, ou seja, enquanto $60 \%$ dos estudantes brancos, na faixa etária de 15 a 17 anos, cursam o ensino médio, no caso dos negros apenas $32 \%$, e no ensino superior a diferença porcentual é ainda maior, enquanto $53,6 \%$ dos estudantes brancos, entre 20 e 24 anos, estão na universidade, entre os negros nessa mesma faixa etária a taxa é de $15,8 \%$.

Dados do IBGE (2011) indicam que a presença de estudantes pretos e pardos no ensino superior subiu de 1,8\%, em 1997, para 8,8\%, em 2011, enquanto para os brancos essa porcentagem é de $25 \%$, permitindo afirmar que a representatividade de pretos e pardos em comparação 
com os brancos nas instituições de ensino superior permanece baixa. Os dados mostram também que, mesmo depois de mais de uma década de formulações de políticas afirmativas que visam a amenizar as barreiras que impedem a ascensão social, econômica e educacional dos grupos estigmatizados - negros e indígenas -, a desigualdade ainda é bastante expressiva entre os grupos étnico-raciais. É importante assinalar que esse aumento significativo no percentual de pretos e pardos no nível superior é, em parte, resultado do sistema de cotas raciais, do Prouni e do Fies.

Em relação ao acesso dos negros no ensino superior, Queiroz (1999, p. 217) assinala que "as desvantagens que pretos e pardos vão acumulando ao longo da sua trajetória pelo sistema de ensino parecem se expressar com mais nitidez no ensino superior”. A autora observa que neste nível de ensino os pretos e pardos são pouco representados e até mesmo ausentes em determinadas áreas e carreiras mais prestigiadas, o que significa dizer que estes "não estão se beneficiando daquelas carreiras mais tradicionais, mais valorizadas socialmente ou daquelas ocupações que envolvem comando, que representam a possibilidade de ascensão social; essas seguem sendo espaços cativos dos brancos”. Afirma ainda que é no ensino superior que "o sistema de ensino revela [...], com maior crueza, a sua face perversa de reprodutor das desigualdades sociais” (Queiroz, 1999, p. 217).

As oportunidades educacionais também são menores para os pretos e pardos em comparação com os brancos de mesma origem social. Isso se dá, segundo Hasenbalg (2005, p. 230), “devido ao efeito de práticas discriminatórias sutis e de mecanismos racistas mais gerais”. Acrescenta o autor citado que os brancos têm uma vantagem substancial em relação aos pretos e pardos de mesmo nível educacional no preenchimento de posições ocupacionais superiores, assim como um grande diferencial de renda, que se explica pela discriminação ocupacional (Hasenbalg, 2005); 
vantagem decorrente de privilégios que os acompanham desde os primórdios da formação da nação brasileira, isto é, desde o período colonial; privilégios que a elite branca racista não irá abrir mão facilmente.

Costa (2006, p. 218) afirma que "num país que discrimina negros, os brancos, mesmo que não sejam agentes diretos do racismo, são os beneficiários materiais das desigualdades produzidas pelas adscrições raciais”. Complementando a afirmação de Costa, Queiroz (2002, p. 15) salienta que

qualquer que seja o âmbito e a dimensão observada, negros e brancos estão desigualmente situados com relação ao acesso às oportunidades. É assim no mercado de trabalho, na educação e em qualquer outro espaço da vida brasileira.

Segundo a autora citada,

a herança da escravidão tem sido invocada como argumento para justificar a situação presente de desvantagem da população negra. No entanto, este argumento revela-se frágil diante do longo tempo decorrido desde a extinção do trabalho escravo (Queiroz, 2002, p. 15).

Acrescenta ainda que:

A fragilidade dessa explicação se evidencia quando se observa que as precárias condições econômicas dos negros, no pós-abolição, não diferiam muito daquela dos grupos de trabalhadores estrangeiros brancos que chegaram ao Brasil. Hoje, boa parte da elite econômica, política e intelectual do país é oriunda desses grupos de imigrante pobres, enquanto que a situação da maioria da população negra manteve-se quase que inalterada. Assim, não há como explicar as precárias condições de existência dos negros hoje, a não ser pelo efeito devastador do racismo (p. 15).

Verifica-se, assim, que, se no período escravista os negros (livres ou cativos) eram vistos com seres inferiores, destituídos de direitos, pós-abolição foram abandonados à própria sorte e, diferente dos imigrantes estrangeiros que tiveram políticas públicas para inserção no mercado de 
trabalho e na sociedade brasileira, nenhuma política pública foi criada pensando na população negra (Menezes, 2006). Mesmo o Estado brasileiro tendo criado, nos últimos anos, algumas políticas de promoção da igualdade racial, o racismo, as práticas racistas, o preconceito e a discriminação, os impedem de sair do lugar marginal a que foram relegados desde o momento em que foram sequestrados das suas terras de origens, no continente africano, e para cá trazidos à força e escravizados.

Para Hasenbalg (2005, p. 208), "as desigualdades raciais contemporâneas são apenas residualmente devidas à herança do escravismo e refletem principalmente a operação contínua de princípios racistas de seleção social”; seleção que beneficia, especialmente, a elite branca racista, a qual, como já assinalado, não está disposta a abrir mão dos privilégios que os acompanha desde o início da formação do Brasil, e, para manter seus privilégios, cultiva o racismo como mecanismo de manter os grupos étnico-raciais estigmatizados sobre o seu domínio, isto é, subalternizados e oprimidos.

No que se refere às desigualdades educacionais, Seabra (2009, p. 88) afirma que "a escola da modernidade universalizou-se no acesso, prologou o tempo de permanência de todos, criou a 'escola única', mas só parcialmente se democratizou”. Para a referida autora:

Adiou-se a exclusão escolar explícita para momentos mais tardios, criaram-se novas modalidades de distinção e hierarquização dos públicos escolares, em suma, as desigualdades escolares sofreram uma translação nos tempos e nos espaços em que ocorrem, sem nunca terem deixado de assumir a intensa marca das diferenças sociais (Seabra, 2009, p. 88).

Seabra observa ainda que "a percepção genérica com que se fica é a de assistirmos a um deslocamento das desigualdades para os níveis superiores do sistema escolar, mantendo-se ou renovando-se as desigualdades entre os grupos em cada uma das etapas de orientação” (2009, p. 88). Pode-se dizer 
que as desigualdades escolares que atingem a população pobre brasileira em todos os níveis e modalidade de ensino, sobretudo nos superiores (Graduação e Pós-Graduação), atingem com mais intensidade a população negra.

\section{AS DESIGUALDADES EDUCACIONAIS NA REGIÃO NORDESTE E NA BAHIA}

Como já assinalado, o Brasil apresenta grandes desigualdades sociais, econômicas e culturais. Os indicadores sociais revelam, no entanto, que estas desigualdades são mais acentuadas nas regiões menos desenvolvidas economicamente. Enquanto no Sudeste a porcentagem de pessoas que vivem na pobreza é de $11 \%$, no Nordeste esse porcentual é de $40 \%$, e a renda per capita é três vezes menor. A deficiência no acesso a direitos humanos básicos como saúde, educação, moradia, saneamento, entre outros, são algumas das dificuldades que o país, em particular as regiões mais pobres (norte e nordeste), encontra para vencer a barreira da linha da pobreza. De acordo com os estudos de Santos (2013), no conjunto da população pobre brasileira, $64 \%$ dos pobres são negros e $70 \%$ dos indigentes.

A disparidade na concentração de renda é gritante entre os que se encontram no topo da pirâmide social em relação aos que estão na base. Enquanto uma pequena parcela da população (10\%) detém a maior parte da renda e da riqueza do país, a grande maioria encontra-se em situação de pobreza, e um porcentual significativo em situação de extrema pobreza. Segundo o Relatório do Desenvolvimento Humano (2011), divulgado pelo Programa das Nações Unidas (PNUD), e o Índice de Desenvolvimento Humano (IDH), mais de 5 milhões de brasileiros vivem em situação de pobreza, e cerca de 70\% da população encontra-se em situação de vulnerabilidade, podendo passar por privações.

A desigualdade de renda entre os grupos de cor/raça, assim como entre Regiões, Estados e municípios, é bastante acentuada entre os grupos mais afortunados e os menos favorecidos. A média mensal de rendimento 
dos brancos é de $\mathrm{R} \$ 1.538,00$, amarelos $\mathrm{R} \$$ 1.574,00, valores que chegam próximo do dobro do valor relativo aos grupos menos favorecido; os pretos

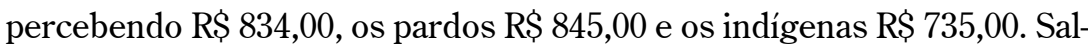
vador é a capital com a maior desigualdade de rendimento entre brancos e pretos, isto é, o rendimento dos brancos é 3,2 vezes maior que a dos pretos, e 2,3 em relação aos pardos (IBGE, 2011). Ainda de acordo com as análises do IBGE (2008, p. 213),

A distribuição destes grupos entre os $10 \%$ mais pobres e entre o $1 \%$ mais rico mostra que enquanto entre os mais pobres, em 2007, os brancos apenas alcançam pouco mais de $25 \%$ do total, entre os que estão na classe mais favorecida, eles representam mais de $86 \%$. Por sua vez, os pretos e pardos são quase $74 \%$ entre os mais pobres e só correspondem a pouco mais de $12 \%$ entre os mais ricos. Estes valores mostram que as desigualdades raciais na apropriação da renda do País têm se mantido ou até piorado um pouco, se comparadas com as dos anos anteriores.

Os dados do IBGE revelam nitidamente a grande diferença porcentual entre brancos e negros, tanto no grupo dos mais ricos como dos mais pobres. Pereira (2008) e Santos (2013) são enfáticos ao afirmar que no Brasil tanto o poder como a pobreza tem cor. Corroborando com a afirmação de Pereira e de Santos, Nascimento (2003) ressalta que na hierarquia da renda, "raça" é fator determinante.

Conforme os dados do IBGE (2008, p. 209) sobre as condições de vida da população brasileira, transcorrido mais de 120 anos da abolição da escravatura "a desigualdade material e simbólica da população composta pelos grupos étnico-raciais subalternizados se manteve e a desvantagem em relação aos brancos no usufruto de recursos e benefícios continua a afetar severamente metade da população brasileira”. População que possui mais da metade $(50,7 \%)$ de negros. Essa observação do IBGE corrobora para o que afirmam Hasenbalg $(1997,2005)$ e Queiroz $(1999,2002)$ : as práticas racistas são as grandes responsáveis pela situação marginal em que pretos e pardos se encontram no país. 
Conforme os dados do Censo de 2010 (IBGE, 2011), a população brasileira é composta de: $47,7 \%$ de brancos, $7,6 \%$ de pretos, $43,1 \%$ de pardos, $1,1 \%$ de amarelos e $0,4 \%$ de indígenas, sendo nas Regiões Norte e Nordeste onde se concentra o maior número de pardos e pretos da população brasileira, e no Sul e Sudeste o maior número de brancos. Se, no entanto, se tomarmos como parâmetro a compreensão de que pretos e pardos fazem parte do mesmo grupo étnico-racial, a população negra, somando essas duas categorias, como observado no paragrafo anterior, corresponde a mais da metade da população do país, $50,7 \%$. No Censo de 2000 essa porcentagem era de 44,7\%. De acordo com as análises do IBGE (2011), uma das hipóteses que explica esse aumento de 6\% é a maior valorização da identidade negra.

Hasenbalg (1997, p. 64), todavia, nos chama a atenção para o fato de que:

As pessoas que se declaram pretas e pardas nas pesquisas do IBGE estão concentradas na base da distribuição de renda e sobre-representadas nas situações de pobreza e indigência. A população não-branca está, então, claramente concentrada nos bolsões de pobreza: no nordeste, particularmente no nordeste rural, nas periferias das regiões metropolitanas e na rede de cidades pequenas e médias do interior.

Isto permite afirmar que, além de cor, como afirmam Pereira (2008) e Santos (2013), a pobreza tem endereço no Brasil - as Regiões Norte e Nordeste. Afirmação essa que parte do princípio que, como vem sendo demonstrando neste artigo, essas duas regiões é onde se concentra o maior percentual de pobres e de negros do país.

No que se refere à educação, como podemos perceber, as oportunidades educacionais entre pobres e ricos, brancos e negros, são extremamente desiguais. Quanto mais pobre e/ou escura for a cor da pele do sujeito, menor será o seu nível de escolaridade. Segundo Cury (2002, p. 258), “a pirâmide educacional acompanha muito de perto a pirâmide da 
distribuição da renda e da riqueza”. Em todos os espaços sociais, notadamente no espaço educacional formal, existe um enorme fosso entre os grupos mais favorecidos e os menos favorecidos, e que permite se afirmar que a educação oferecida à elite não é a mesma oferecida à população de baixa renda.

Mesmo com a "democratização" e "universalização" do Ensino Fundamental e uma crescente expansão do Ensino Médio, os grupos menos favorecidos e historicamente discriminados continuam à mercê de um sistema educacional que não atende as suas demandas e os seus interesses, tampouco oferece as condições básicas - recursos humanos especializados, materiais didáticos apropriados as suas necessidades, estrutura física adequada, etc. - necessárias para um bom desempenho social e intelectual do aluno (Araújo, 2012). Como salienta Tavares Junior (2011, p. 553), "a expansão das matrículas não cumpriu a expectativa de que ela seria capaz de diminuir as desigualdades sociais”. A meu ver, criou apenas a falsa ideia de que os grupos menos favorecidos estão tendo as mesmas oportunidades educacionais dos grupos mais favorecidos.

Para Bourdieu (1998), a mera expansão dos sistemas escolares não é suficiente para acabar com a exclusão que os grupos menos favorecidos e historicamente discriminados sofrem no ambiente educacional. Afirma ainda que "não é suficiente enunciar o fato da desigualdade diante da escola, é necessário descrever os mecanismos objetivos que determinam a eliminação contínua das crianças desfavorecidas” (p. 41). Como podemos perceber esses mecanismos estão diretamente ligadas às questões sociais, raciais, econômicas e geográficas, como tem sido enfatizando no decorre deste estudo.

Mesmo os dados oficiais (IBGE, 2010) apontando que nos últimos anos o Brasil, principalmente a Região Nordeste, melhorou significativamente a oferta de vagas na educação pública e uma queda expressiva na taxa de analfabetismo, os índices de desenvolvimento educacionais do país 
ainda são baixos para os padrões internacionais. A população não alfabetizada (IBGE, 2010), com 15 anos ou mais de idade, embora tenha reduzido para 9,6\% em 2010, ainda é considerada alta. As Regiões Sul (5,1\%) e Sudeste $(5,5 \%)$ são as que apresentam as menores taxas de analfabetismo, e a Região Nordeste a mais alta (19,1\%), seguida da Região Norte (11,2\%), o que confirma a disparidade existente entre as regiões economicamente mais desenvolvidas e as menos desenvolvidas.

Os dados do IBGE revelam que o número médio de anos de estudos das pessoas de 10 anos ou mais de idade também é expressivo entre as regiões economicamente mais desenvolvidas e as menos desenvolvidas. Conforme os dados da PNAD 2009 (IBGE, 2010), a média nos anos de estudos dos brasileiros é de 7,2 , e que nas Regiões Sudeste $(7,8)$, Sul $(7,6)$ e Centro-Oeste $(7,5)$ essa média é maior que a nacional, enquanto no Norte $(6,7)$ e no Nordeste $(6,0)$ esta média cai significativamente. O Estado da Bahia, nos últimos anos, vem atingindo, e até mesmo superado, as metas propostas por órgãos nacionais e internacionais no acesso à educação, no entanto ainda não conseguiu atingir o índice nacional, e encontra-se entre os Estados com os piores índices educacionais no país, tanto no Ensino Fundamental como no Ensino Médio, ressaltando que a taxa de analfabetismo no Estado chega a 16,6\%, quase o dobro da taxa nacional.

As disparidades existentes em todos os níveis e modalidades de ensino, portanto, estão cada vez mais acentuadas entre os diferentes grupos sociais e étnico-raciais. No decorrer deste artigo podemos perceber que os pretos, os pardos e os indígenas estão em desvantagens perante os brancos, e que nas Regiões Norte e Nordeste essas desvantagens são bem mais exacerbadas que nas outras regiões do país.

Para Silva e Hasenbalg (1998, p. 14), "a questão educacional parece estar se constituindo no nó górdio das desigualdades raciais em nosso país”. Acrescentam ainda que 
a expansão do ensino no Brasil continua funcionando de forma discriminatória, tendo os pretos e pardos menos oportunidades de treinamento que os brancos, o que reforça a desigualdade da competição antes da entrada no mercado de trabalho (p. 4).

Se, portanto, o racismo e as práticas racistas são fatores determinantes das desigualdades sociais e educacionais, a origem étnico-racial do sujeito atrelado a seu nível de escolaridade, são fatores determinantes na competição por melhores cargos e salários no mercado de trabalho.

Retomando a questão do analfabetismo, incluindo o fator cor/raça e região, os dados do Censo 2010 mostram que, no Brasil, o número de pessoas brancas, com 15 anos ou mais de idade não alfabetizadas, é de 5,9\%, enquanto o número de pessoas pretas é de $14,4 \%$, pardas $13 \%$ e indígenas $23,3 \%$. A tabela a seguir mostra o quanto são díspares os porcentuais de analfabetismo entre regiões e grupos cor/raça.

Distribuição porcentual de pessoas com 15 anos ou mais de idade que não sabem ler e escrever, por região e grupo cor/raça

\begin{tabular}{|l|l|l|l|l|l|l|}
\hline & Geral & Branca & Preta & Parda & Amarela & Indígenas \\
\hline Norte & 11,2 & 7,9 & 16,8 & 11,3 & 9,8 & 32,0 \\
\hline Nordeste & 19,1 & 15,0 & 22,6 & 20,4 & 18,3 & 23,6 \\
\hline Sudeste & 5,5 & 3,8 & 8,9 & 7,3 & 3,9 & 10,3 \\
\hline Sul & 5,1 & 4,0 & 9,6 & 9,4 & 5,3 & 15,8 \\
\hline Centro-Oeste & 7,2 & 5,2 & 11,9 & 8,1 & 5,0 & 21,6 \\
\hline
\end{tabular}

Fonte: IBGE (2011).

Como podemos ver na tabela anterior, a taxa de analfabetismo entre regiões também é expressiva. O Norte e o Nordeste seguem apresentando as piores taxas de pessoas não alfabetizadas em comparação com as outras regiões brasileiras, notadamente entre os grupos cor/raça preta, parda e indígena. Ou seja, uma realidade bastante incômoda e desigual em comparação com as regiões mais desenvolvidas economicamente. 
De acordo com as análises do IBGE (2008, p. 41) sobre as condições de vida da população brasileira,

a educação, como processo de acumulação de conhecimento, é o ganho social que mais enobrece a natureza humana, em contrapartida o analfabetismo é um fator de marginalização, que exclui e impede a mobilidade social da criança, do jovem, do homem e da mulher.

Diante do que vem sendo apresentado, pode afirmar-se que nesse processo desigual e excludente de acesso e acumulação de conhecimento, a população negra, sem dúvida nenhuma, é a mais prejudicada.

Outro dado preocupante e que deve ser levado em consideração na comparação entre regiões ricas e pobres é o desempenho educacional dos estudantes. O Ideb (2011) revela que as melhores escolas do país estão concentradas na Região Sul e Sudeste, enquanto as piores estão no Norte e Nordeste, sendo Alagoas e Bahia os Estados em que se localiza o maior número de municípios com as notas mais baixas na avaliação do desempenho educacional dos alunos, ou seja, os piores índices de desenvolvimento educacional do país.

Para Reiter e Dias (2005), os fatores estruturais que emperram o sucesso mais duradouro da reforma educacional empreendida no Brasil e na Bahia são:

a permanência de práticas de cunho racista e elitista que permeiam toda a sociedade brasileira garantindo a manutenção de uma situação de privilégio face aos grupos populares e a divisão da educação em dois sistemas - um para a perpetuação da exclusão, e outro para a manutenção de privilégio (p. 112). 
Percebe-se que, enquanto os grupos mais favorecidos tem uma educação de qualidade, em escolas privadas, os grupos menos favorecidos são direcionados a uma escola pública que não lhes oferece os elementos necessários para tirá-los do lugar subalterno a que foram condicionados, para o desenvolvimento social, intelectual e profissional destes.

O ensino público, no Brasil, é tão ruim que, conforme o Índice de Desenvolvimento da Educação Básica - Ideb (Índice..., 2011) -, numa escala de 0 a 10, a média das notas das escolas públicas brasileiras é 4,7 nos anos iniciais do Ensino Fundamental; 3,9 nos anos finais do Ensino Fundamental; e 3,4 no Ensino Médio. Na Bahia, esses índices ficaram bem abaixo da média nacional: 4,2 nos anos iniciais, 3,3 nos anos finais e 3,2 no Ensino Médio, evidenciando que a cada etapa do ensino essa média é menor, reflexo, dentre outros fatores, da má qualidade do ensino oferecido, das desigualdades educacionais e das práticas racistas.

Reiter e Dias (2005) afirmam que as escolas públicas brasileiras, em particular as baianas, foram transformadas em escolas dos excluídos. Assinalam que, enquanto as escolas privadas são vistas e idealizadas como a "escola padrão”, verdadeiros "espaços brancos”, as escolas públicas se mantêm como "espaço negro", sinônimo de baixa qualidade, pouca ou nenhuma aprendizagem significativa, desempenho e compromisso questionáveis dos profissionais nelas alocados. Ponderam ainda que:

Estas representações sociais da escola pública devem se tornar um dos pontos constantes das agendas públicas, seja dos órgãos representativos de classe, seja da sociedade civil organizada ou das esferas governamentais, uma vez que tem ferido de morte todo o trabalho positivo que tem sido feito em muitas das escolas das redes municipal e estadual de educação (p. 111).

Diante dos dados apresentados, percebe-se que as práticas racistas, a má distribuição de renda e as oportunidades educacionais diferenciadas, são as principais causas das desigualdades sociais e educacionais no país. 
Nota-se também que as desigualdades sociais que permeiam a sociedade brasileira são cada vez mais acentuadas e atingem, principalmente, os grupos historicamente discriminados (negros e indígenas) e as regiões mais pobres (Norte e Nordeste), produto do processo histórico de formação do país e, sobretudo, das práticas racistas. Concordo com Silva (2007, p. 167), quando ela afirma que:

se a educação não pode ser pensada como alheia aos conflitos sociais e às contradições da nação, ela merece ser pensada como agente importante de reflexão na busca de políticas mais atentas à diversidade e às formas de preconceito.

Para a professora Ana Célia da Silva, ${ }^{2}$ o racismo, em grande parte, sem desconsiderar o capitalismo, é a principal causa das desigualdades na sociedade brasileira, ocultando a dimensão étnico-racial na forma como se efetiva a distribuição de renda e de oportunidades sociais nas Regiões Norte e Nordeste, onde habita uma maioria de negros e indígenas. A fala da referida professora e os dados apresentados neste estudo, permitem afirmar-se que as relações sociais, principalmente as étnico-raciais, no Brasil, estão cada vez mais desiguais, complexas e excludentes, e que as relações de poder demarcam o lugar que os sujeitos ocupam na hierarquia social. Em outras palavras, pode-se afirmar que onde quer que o sujeito interaja a sua situação econômica e a cor da sua pele lhe conferem vantagens ou desvantagens que o diferencia dos demais, isto é, que o coloca num lugar de superioridade ou de inferioridade.

Ante tal cenário surgem alguns questionamentos: Podemos falar em democratização da educação se os sujeitos pertencentes aos grupos menos favorecidos e historicamente discriminados continuam excluídos dentro da escola à qual estão sendo incluídos? Que educação é essa que

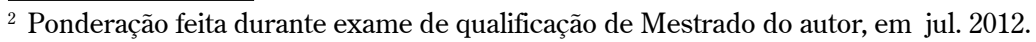


se pretende democrática, mas que não respeita a diversidade étnico-racial e cultural do povo brasileiro, presente no espaço escolar? Que educação é essa que não respeita a singularidade dos indivíduos? Qual o papel da escola, homogeneizar ou diversificar saberes? Responder esses questionamentos escapa aos propósitos deste artigo, requerendo estudos mais aprofundados, no entanto pode-se afirmar que a escola que se pensa democrática ainda continua discriminando e excluindo do seu espaço todos os sujeitos que não se enquadram dentro dos padrões socialmente construídos pela cultura hegemônica.

Cavalleiro (2001, p. 147) nos chama a atenção para o fato de que “ao se achar igualitária, livre de preconceito e da discriminação, muitas escolas têm perpetuado desigualdades de tratamento e minado efetivas oportunidades igualitárias a todas as crianças”. O pensamento de Cavalleiro é corroborado por Bourdieu (1998, p. 53), quando afirma que "a igualdade formal que pauta a prática pedagógica serve como máscara e justificação para a indiferença no que diz respeito às desigualdades reais diante do ensino e da cultura transmitida, ou melhor dizendo, exigida”. Resumindo, Cavalleiro e Bourdieu nos chamam a reflexão para o fato de que a educação formal, mesmo depois do processo de democratização e universalização, continua bastante desigual, favorecendo os mais favorecidos e desfavorecendo os menos favorecidos.

Segundo Silva (2007, p. 83),

pensar a educação no mundo globalizado é pensar sobre um "valor", entendido aqui como colocado na ética da responsabilidade, tencionando pela efemeridade e pela velocidade dos processos sociais, culturais, políticos e econômicos.

Ainda, de acordo com a autora citada,

Significa estar disposto a pensar sobre a concentração de saberes que possam articular, de forma criativa, as demandas diaspóricas que embaralham as identidades, até então asseguradas pelo teto político 
do Estado-nação, as diversas temporalidades que circulam incessantemente no mundo da cultura e, sobretudo, pensar uma educação para a alteridade, para a descentração do sujeito cartesiano, uma educação para além da noção de identidade cultural, como até então era entendida e vivenciada com suas matrizes essencialistas e naturalizantes (Silva, 2007, p. 83).

Nesse sentido, pode se dizer que, na atualidade, as discussões em torno da educação das relações étnico-raciais fazem-se cada vez mais necessárias pela urgência de mudanças que oportunizem uma educação para todos, pois, o que fez o Estado foi buscar a universalização do ensino, sem se preocupar com a qualidade e a igualdade de oportunidades. Nessa direção, Scotti $(2007$, p. 5) assevera que:

a idéia de que a igualdade de acesso propicia igualdade de chances só poderia ocorrer se vários atributos e condições sociais dos indivíduos fossem constantes. Como não os são, a idéia de igualdade de acesso não pode ser confundida com igualdade de chances.

Assim, diante dos dados apresentados, pode afirmar-se que universalizar não é o mesmo que democratizar. Existe uma diferença abissal entre ambos. Democratizar significa ir além da garantia de acesso. Uma escola que se pense democrática oferece a todos os seus alunos/as, independente de pertencimento étnico-racial e/ou cultural, de religião, de orientação sexual, entre outras formas de diferenciação social, igualdade de oportunidade; o que a escola não tem feito (Araújo, 2012). Concordo com Haddad (2007, p. 42), quando afirma que "estamos distantes de um ensino sem discriminação, que promova igualdade de acesso a todos e todas, independentemente de raça, sexo, origem ou idade”.

Afinal, como sustenta Dubet (2008, p. 28), “a escola não conseguiu neutralizar os efeitos das desigualdades culturais e sociais sobre as desigualdades escolares". Em graus diversos, os alunos mais privilegiados em capital cultural, social e econômicos apresentam rendimentos escolares melhores e têm níveis mais elevados de estudos, e frequentam os cursos 
mais prestigiados e rentáveis que os outros. Acrescenta, ainda, que "se o acesso aos bens escolares se expandiu, as habilitações e as formações mais prestigiosas permanecem quase monopólio dos grupos mais favorecidos, enquanto os menos favorecidos monopolizam, por sua vez, as habilitações mais curtas e menos rentáveis” (Dubet, 2008, p. 27).

\section{CONSIDERAÇÕES FINAIS}

Mesmo diante de tantas desigualdades no campo educacional, ainda é consenso que a educação constitui caminhos para solucionar ou amenizar mazelas existentes na sociedade. É consenso também que o investimento em educação é a melhor solução para diminuir as desigualdades sociais nos países onde a distribuição de renda é extremante desigual (ARAÚJO, 2012). Cabe, portanto, saber se a escola, que se diz libertadora, irá de fato pôr em prática uma abordagem pedagógica que atenda às demandas, interesses e necessidades dos grupos menos favorecidos, uma vez que, como afirma Saviani (2008), a escola é um aparelho ideológico do Estado a serviço de uma classe. Considera-se que nunca foi do interesse das elites que os grupos subalternizados tenham acesso ao conhecimento científico e aos saberes sistematizados.

As pesquisas desenvolvidas por órgãos governamentais e não governamentais, universidades, entre outros, são bastante claras e objetivas nos resultados sobre as desigualdades educacionais que separam os grupos afortunados dos grupos subalternizados. Como visto no decorre deste artigo, as desigualdades visíveis, identificadas e quantificadas que perpassam pelo sistema escolar brasileiro, parecem servir apenas para mostrar o que todos sabem: no Brasil, as oportunidades educacionais não são iguais para todos, e pouco contribuem para que os sujeitos dos grupos menos favorecidos se desenvolvam de forma plena, assim como para melhorarem suas condições de vida. 
Em linhas gerais, pode afirmar-se que, mesmo com a democratização e processo de universalização da educação básica, os grupos menos favorecidos, notadamente a população negra e a indígena, continuam sendo excluídos do sistema de ensino formal em razão de uma série de fatores, entres esses, o currículo que não respeita a diversidade étnico-racial e cultural do povo brasileiro, presente nos diferentes espaços educacionais. Como observa Bourdieu (1998), a escola sempre foi excludente. Hoje, exclui de maneira contínua, em todos os níveis de ensino, mantendo em seu interior aqueles que ela rejeita, contentando-se em relegá-los para os ramos mais desvalorizados, o que a torna um espaço de marginalização dos grupos menos favorecidos.

É importante ressaltar que a melhoria na qualidade da educação pública no Brasil não depende apenas de investimentos e de recursos humanos qualificados, mas também do esforço mútuo entre o Estado, a escola, os profissionais da educação e a sociedade como um todo. Sem essa união, continuaremos sujeitos a uma educação que só atende aos interesses ideológicos da elite, uma educação para manter o grosso da população ignorante e subordinada a uma pequena minoria que está no poder.

Enfim, cabe a todos, principalmente aos governantes, proporcionar aos educandos inseridos nas instituições escolares uma educação pública, democrática e de qualidade, a qual garanta a todos o ingresso, a permanência e o êxito. Não é admissível que as políticas públicas educacionais priorizem apenas uma parcela mínima da população, por meio de uma educação homogeneizadora, deixando à margem ou à "própria sorte" o futuro das crianças e jovens pobres inseridos nos mais diversos contextos sociais e culturais.

\section{REFERÊNCIAS}

ARAÚJO, J. A. Educação, desigualdade e diversidade: os grupos menos favorecidos frente ao sistema escolar brasileiro. Revista da $A B P N$, v. 4, n. 8, p. 114-125, jul./out. 2012. Disponível em: <www.apnb.org.br/Revista/index.php/ edições/articles/257/222>. Acesso em: 18 nov. 2012. 
ARROYO, M. G. Pedagogias em movimento - o que temos a aprender dos movimentos sociais? Currículo sem Fronteiras, v. 3, n. 1, p. 28-49, jan./jun. 2003.

O direito à educação ameaçado: segregação e resistência. In: ARROYO, Miguel González; ABRAMOVICZ, A. (Orgs.). A reconfiguração da escola: entre a negação e a afirmação de direitos. Campinas, SP: Papirus, 2009. p. 129-159.

BARCELOS, L. C. Educação e desigualdades raciais no Brasil. Cad. Pesqui. [on-line]. 1993, n. 86, p. 15-24. Disponível em: <http://educa.fcc.org.br/pdf/ cp/n86/n86a02.pdf $>$. Acesso em: 10 jan. 2012.

BOCK, A. M. B. A desigualdade social e a educação: a dimensão subjetiva do processo educacional. CONGRESSO NACIONAL DE PISCOLOGIA ESCOLAR E EDUCACIONAL, 9., 2009, São Paulo, 2009. Anais... São Paulo: UPM, 2009.

BOURDIEU, P. Escritos de educação. 8. ed. Petrópolis, RJ: Vozes, 1998.

CASTRO, J. A. Evolução e desigualdade na educação brasileira. Educ. Soc., Campinas, vol. 30, n. 108, p. 673-697, out. 2009. Disponível em: <www.cedes. unicamp.br>. Acesso em: 20 jan. 2012.

CAVALLEIRO, E. Educação anti-racista: compromisso indispensável para um mundo melhor. In: CAVALLEIRO, E. (Org.). Racismo e anti-racismo na educação: repensando nossa escola. São Paulo: Selo Negro, 2001. p. 141-160.

COSTA, S. Dois Atlânticos: teoria social, anti-racismo, cosmopolitismo. Belo Horizonte: Editora UFMG, 2006.

CURY, C. R. J. Direito à educação: direito à igualdade, direito à diferença. $\mathrm{Cad}$. Pesqui. [on-line]. 2002, n.116, p. 245-262. Disponível em: <www.scielo.br/pdf/ cp/n116/14405.pdf $>$. Acesso em: 5 fev. 2012.

DUBET, F. O que é uma escola justa? A escola das oportunidades. São Paulo: Cortez, 2008. 
FRANÇA, S. F. Uma visão geral sobre a educação brasileira. Integração, v. 1, p. 75-88, 2008. Disponível em: <www.upis.br/posgraduacao/revista_integracao/ educacao_brasileira.pdf>. Acesso em: 8 jan. 2012.

GOMES, N. L. O movimento negro no Brasil: ausências, emergências e a produção dos saberes. Política \& Sociedade, vol. 10, n. 18, p. 133-154, abr. 2011. GONÇALVES, L. A. O.; SILVA, P. B. G. Movimento negro e educação. Revista Brasileira de Educação, São Paulo, set./out./nov./dez. n. 15, p. 134-158, 2000. HADDAD, S. Educação e exclusão no Brasil. São Paulo: Ação Educativa, 2007. HASENBALG, C. Discriminação e desigualdades raciais no Brasil. 2. ed. Belo Horizonte: UFMG; Rio de Janeiro: Iuperj, 2005.

. O contexto das desigualdades raciais. In: SOUZA, J. (Org.). Multiculturalismo e racismo: uma comparação Brasil - Estados Unidos. Brasília: Paralelo 15, 1997. p. 63-68.

ÍNDICE de Desenvolvimento da Educação Básica. IDEB. 2011. Disponível em: <http:/www.portalideb.com.br>. Acesso em: 4 set. 2012.

INSTITUTO Brasileiro de Geografia e Estatística. IBGE. Indicadores Sociais Municipais: uma análise dos resultados do universo do Censo Demográfico 2010. Estudos \& Pesquisas: informações demográfica e socioeconômica, Rio de Janeiro, n. 28, 2011.

INSTITUTO Brasileiro de Geografia e Estatística. IBGE. Pesquisa Nacional por Amostra de Domicílios: sínteses dos indicadores 2009. Rio de Janeiro, 2010. INSTITUTO Brasileiro de Geografia e Estatística. IBGE. Síntese de Indicadores Sociais: uma análise das condições de vida da população brasileira. Estudos \& Pesquisas: informações demográfica e socioeconômica, Rio de Janeiro, n. $23,2008$.

KLEIN, R. Como está a educação no Brasil? O que fazer? Ensaio: Aval. Pol. Públ. Educ., Rio de Janeiro, v. 14, n. 51, p. 139-172, abr./jun. 2006.

MENEZES, Jaci Maria Ferraz de. Construindo a vida: relações raciais e educação na Bahia. Cadernos Penesb, n. 8, p. 98- 10, dez. 2006. 
NASCIMENTO, E. L. O sortilégio da cor: identidade, raça e gênero no Brasil. São Paulo: Summus, 2003.

OLIVEIRA, Romualdo Portela; ARAUJO, Gilda Cardoso de. Qualidade do ensino: uma nova dimensão da luta pelo direito à educação. Revista Brasileira de Educação. N. 28, p. 5-24, Jan./Fev./Mar./Abr., 2005.

PEREIRA, Amauri Mendes. Trajetória e perspectivas do movimento negro brasileiro. Belo Horizonte: Nandyala, 2008.

QUEIROZ, D. M. Desigualdades raciais no ensino superior no Brasil: um estudo comparativo. In: QUEIROZ, D. M. (Coord.). O negro na universidade. Salvador: Novos Toques, 2002.

. "Raça" e educação na Bahia nos anos 90. Revista da FAEEBA - Educação e Contemporaneidade, Salvador, nº 12, p. 199-221, jul./dez. 1999.

REITER, B.; DIAS, R. C. Reforma educativa, exclusão e racismo na Bahia. Gestão em Ação, Salvador, v.8, n.1, p. 97-116, jan./abr. 2005.

SANTOS, I. A. A. Direitos Humanos e as práticas de racismo. Brasília: Câmara dos Deputados, edições Câmara, 2013. Disponível em: <http://bd.camara. gov.br/bd/bitstream/handle/bdcamara/13516/direitos_humanos_santos. pdf?sequence=3>. Acesso em: 27 set. 2013.

SAVIANI, D. Escola e democracia: teoria da educação, curvatura da vara, onze teses sobre educação política. 40. ed. Campinas, SP: Autores Associados, 2008. SEABRA, T. Desigualdades escolares e desigualdades sociais. Sociologia, Problemas e Práticas, n. 59, 2009, p. 75-106.

SCOTTI, P. A. Igualdade de chances entre grupos como critério de equidade em educação. CONGRESSO BRASILEIRO DE SOCIOLOGIA, 13., 2007, Recife. Anais... Recife (PE): Ufpe. 29 de maio a $1^{\circ}$ de junho de 2007.

SILVA, A. C. Desconstruindo a discriminação do negro no livro didático. 2. ed. Salvador: Edufba, 2010.

SILVA, M. A. Formação de educadores/as para o combate ao racismo: mais uma tarefa essencial. In: CAVALLEIRO, Eliane (Org.). Racismo e anti-racismo na educação: repensando nossa escola. São Paulo: Selo Negro, 2001. p. 65-83. 
SILVA, M. L. Educação, etnicidade e preconceito no Brasil. Santa Cruz do Sul: Edunisc, 2007.

SILVA, N. V.; HASENBALG, C. Tendências da desigualdade educacional no Brasil. Dados, Rio de Janeiro, vol. 43, n. 3, 2000.

. Educação e diferenças raciais na mobilidade ocupacional no Brasil. ENCONTRO ANUAL DA ANPOCS, 22., 27 a 31 de outubro de 1998, Caxambu, MG. Anais... Caxambu, MG, 1998.

SOARES, J. F. S.; ALVES, M. T. G. Desigualdades raciais no sistema brasileiro de educação básica. Educação e Pesquisa, São Paulo, v. 29, n. 1, p. 147-165, jan./jun. 2003.

TAVARES JÚNIOR, F. Limites sociais das políticas de educação: equidade, mobilidade e estratificação social. Inter-Ação, Goiânia, v. 36, n. 2, p. 539-557, jul./dez. 2011.

Recebido em: 5/9/2013

Revisado em: 4/10/2013

Aceito em: 15/10/2013 